\title{
El Museo Guatemalteco
}

Cundoo El Museo Guatemalteco empieza su publicación el $3 \mathbf{I}$ de octubre de I856, el general Rafael Carrera, declarado presidente vitalicio de Guatemala dos años antes, empuñaba con mano dura las riendas del poder. La reacción conservadora, entonces en su apogeo, había borrado por completo las reformas liberales intentadas por Francisco Morazán y Mariano Gálvez, y en la república regía la censura previa.

Las palabras iniciales del editor Luciano Luna, en el primer número c.e El Museo, responden tanto a esa situación de fuerza en que vivía el país como a la vana y sempiterna aspiración de emancipar el desarrollo cultural de los azares de la inestabilidad política. Tras referirse a la vida transitoria e inútil ce los periódicos guatemaltecos, debido a su participación en las contiendas civiles, el editor promete mantenerse alejado de "esa senda trillada, estéril y escabrosa", 1 esbozando el doble plan ce rescatar del olvido obras de valor y de ofrecer medio de expresión tanto a los intelectuales como a la juventud estudiosa.

Durante tres años y tres meses El Museo elude así los peligros de la política nacional manteniéndose en un cauce estrictamente cultural, pero al fin sucumbe víctima cie las dificultades económicas tan típicas de las publicaciones de su clase. En esos años de vida su impresión no estuvo exenta de contratiempos, sin embargo. Hasta el número 34, de junio I9 de 1857, aparece como revista semanal, publicada generalmente los viernes $\mathrm{y}$, a veces por varias semanas, los jueves; mas a partir del número 35 , de julio I de 1857 , sale también con frecuencia los demás dias de la semana con la excepción del domingo, es decir, los

I P. 6. Años después Luciano Luna se unió a los elementos liberales al servicio de El Salvador para luchar contra la dictadura, pero fue capturado y fusilado por Carrera en 1863. Tenía entonces el grado de teniente coronel. Víctor Miguel Díaz, Breve bistoria del periodismo en Guatemala, Guatemala, 1929, pp. 222224. 
lunes, miércoles o sábados especialmente, y alguna vez los martes o jueves, En el número 44 , de octubre 2 ce 1857 , se anunciaba que "las muchas ocupaciones de la Imprenta"2 habían impedido la aparición del "periódico"3 en sus días señalados y que por el mismo motivo se interrumpía temporalmente su publicación. La interrupción durará cinco meses, agravada por dificultades económicas y por una epidemia de cólera que azotó a la ciudad. Cuando El Museo reanuda su publicación con el número 45, el Io de marzo de 1858 , lo hace con un "Nuevo prospecto" que anuncia su carácter bimestral, aunque en una ocasión va a salir tres veces al mes y en otras dos aparece sólo una vez. Las vicisitudies de la revista alcanzan su punto culminante en el número $\mathrm{I}_{4}$ del segundo volumen, correspondiente al 3 I de diciembre de 1858 , cuando se anuncia su próxima desaparición debido a la desesperada situación económica en que se halla y a la falta de cooperación de "las personas de saber"."4 Mas según el propio aviso, un último esfuerzo para subsistir, el intento de publicar El Museo por dos años más, y con la ayuda del gobierno, había fracasado igualmente, al negar el municipio el permiso solicitado para publicar la historia del Regidor Francisco Fuentes y Guzmán, inédita aún en los archivos de esa corporación. ${ }^{5}$ A mediados del mes siguiente, con el número 16 , del 17 de enero de 1859 , El Museo salía por última vez, desposeído de sus atributos literarios, en una tirada dedicada por completo al asesinato de los tres hijos de don Eduardo Klee.

Con la excepción de ese último número el material publicado en El Museo aparece generalmente bajo ciertas secciones denominadas "Ciencias y Artes", "Variedades", "Noticias varias", "Noticias extranjeras", "Avisos". La sección de "Artes y Ciencias" es substituida en ciertos casos por la de "Literatura" e incluye entonces trabajos sobre diversas manifestaciones artísticas o filosóficas. En la sección de "Variedades" aparecen por lo general poesías y otros trabajos de índole literaria, histórica, cultural.6 Otras secciones que no gozan de igual regularidad son: las de "Teatro de variedades" o "Avisos de teatro", que se inicia con

2 P. 8.

3 Así lo llama siempre el editor.

4 Según el anuncio si la publicación no ha llenado su cometido no ha sido sólo culpa del editor sino de "las personas de saber, que, con muy pocas excepciones, todas se han negado a contribuir con sus escritos, ya por el desaliento que naturalmente inspira la falta de estímulos, ya por el temor de acarrearse desagrados". P. 2. El régimen tiránico de los treinta años, en nada favorable a la libre expresión literaria, o a la cultura en general, esterilizaba así, con el desaliento y el temor, a las mejores mentalidades de Guatemala.

5 El Museo, tomo II, N 14, p. 1. Diciembre 31 de 1858.

6 Como se habrá advertido no hay gran diferencia en el material publicado por las secciones de "Ciencias y artes" o "Literatura" y la de "Variedades". 
la inauguración del Teatro de Variedades, construido por Julián Rivera, y continúa con anuncios y comentarios sobre obras teatrales puestas en escena; la de "Miscelánea", que incluirá acontecimientos de actualidad, curiosidades $\mathrm{y}$, finalmente, hasta chistes y anécdotas; la de anuncios de "Libros" recibidos o de interés; las de "Pensamientos sueltos" o "Pensamientos útiles", "Agricultura", "La fábula",8 "Parte política"9 y otras. 10

Además de las novelas y las obras históricas reproducidas aparte y por entregas, de acuerdo con su plan de publicaciones, ${ }^{\prime \prime}$ se dieron a

7 En una descripción del teatro con su correspondiente crítica de las primeras representaciones celebradas se decía: "La novedad artística del mes ha sido el estreno del Teatro de Variedades, verificado el jueves 25. Felicitamos sinceramente al Sr. Rivera, por haber dotado a Guatemala de un establecimiento que se hacía ya tan necesario, y que parece tan apropiado a la población y gusto de nuestra capital". II, 10,1857, p. 3.

8 La sección así titulada se dedicaba a la narración de mitos clásicos, de los cuales se incluyen diez entre los números 17 y 27 de 1857.

9 El tema de la política local está ausente por completo de esta sección. En ella insertan exclusivamente noticias de otros países centroamericanos, de las actividades del aventurero estadounidense Walker y de la reacción de varios países hispanoamericanos, así como comentarios sobre la política expansionista de los Estados Unidos.

10 Cuando después de una interrupción de cinco meses El Museo Guatemalteca reanuda su publicación el 10 de marzo de 1858, el editor expresa la intención de "dar otra forma a la parte de "Variedades" " la cual, en lo sucesivo ocupará dos pliegos comunes o una signatura separada, y de un tamaño más adecuado, para ir formando un libro como los demás que ha publicado El Museo (I, $\left.\mathrm{N}^{2} 45, \mathrm{p} .1\right)$. Seis meses después se anuncia el "Prospecto de Biblioteca Centromericana" que se publicará por suscripción y a cargo de Miguel Boada y Balmes. La "Biblioteca" se proponia incluir obras de hombres famosos, biografias, poesías, ensayos y lecturas varias (II, $\mathrm{N}^{\circ} 10,1858, \mathrm{pp} .7-8$ ).

Este es el origen de un volumen existente en la Biblioteca Nacional de Guatemala en el que se han encuadernado la "Biblioteca Centro-Americana, El Instructor" y "El Museo Guatemalteco. Parte Literaria y de Variedades". La "Biblioteca" consta de 64 páginas $\mathrm{v}$ contiene biografias de Lamennais, Alejandro Dumás (padre), Martínez de la Rosa, Thiers y Jaime Balmes, escritas por Miguel Boada. Termina con las "Poesías póstumas" del propio filósofo español Balmes. La parte correspondiente a "El Museo Guatemalteco" consiste de diez y seis números y tiene 272 páginas. Incluye dos extensos trabajos en prosa, ya mencionados, "De la filosofía del derecho", por José Antonio Urruela y "Memoria o estudio sobre la literatura y las bellas artes", por Juan García Parra, así como poesías de Juan Diéguez, Fernando Velarde, Francisco González Campos, María Josefa Garća Granados, D. R. Hernández, Angel Saavedra, Jesús Laparra y Manuel Zavala. Las obras de esta sección de "Literatura y Variedades" se identificarán en las notas con las siglas ( $\mathrm{LyV})$.

II Algunas de las obras publicadas fueron: Libro de actas del Ayuntamiento de la Ciudad de Santiago de Guatemala, "comprende los seis primeros años, y desde la fundación de la misma ciudad en 1524 hasta 1530"; 1856; Los bermanos de la costa, o Los bucaneros del siglo xvI, 1856-1857, por Manuel González; Colección de novelas escogidas, 1857 (no son de autores guatemaltecos); Prontuario de todas las reales cédulas, cartas acordadas y órdenes comunicadas a la Audiencia del Antiguo Reino de Guatemala desde el año de 1600 basta 1818, 1857; Compendio de la bistoria de la Ciudad de Guatemala, tomo I, 1857, por 
luz en $E l$ Museo algunos estudios de interés que, en su mayoría, requirieron varios números debido a su extensión. Entre ellos podrían mencionarse los titulados "Literatura nacional" (I, Nos. 8-9, I856) y "Retórica" (I, Nos. I4-22,25, I857), que no llevan nombre de autor; "Cuestiones de estética" (I, No. 8, I856), por Fernando Velarde; "Literatura" (I, Nos. 27-28, 30, 1957), por Rafael Machado; "Del origen de la poesía" (I, Nos. 27-28, 30-4c, I857, LyV) y "De la filosofía del derecho" (I, Nos. I.I6, I858, LyV), por José Antonio Urruela; "De la moral dramática" (I, Nos. II-I3, 1857), por Alberto Lista; y "Memoria o estudio sobre la literatura y las bellas artes" (I, Nos. I-I6, I858, LyV), por Juan García Parra. El trabajo titulado "Literatura nacional" lamenta la carencia de una producción literaria nacional, aunque no de hombres eminentes, y expresa la esperanza de que el futuro desarrollo económico del país produzca una literatura propia. "Retórica" aparece en diez números de la revista y es una serie de conferencias en las que se analizan las distintas partes del discurso. 12 "Cuestiones de estética", de Fernando Velarde, es će los trabajos más cortos, señalando la importancia "jerárquica" de la religión, la ciencia y el arte en la cultura. Algo más extenso, el estudio de Rafael Machado, "Literatura", ve la creación literaria como expresión de la vida nacional, declarándola "voz de un pueblo". Tan larga como la serie de conferencias sobre "Retórica" es la titulada "Del origen de la poesía", por el presbítero José Antonio Ortiz Urruela. En ella se presenta un panorama que recorre ia poesía bíblica, oriental, griega y latina. Alberto Lista, en su ensayo "De la moral dramática", acentúa como caracteres esenciales del teatro la belleza, la originalidad y la gracia del estilo y de expresión, al mismo tiempo que las posibiliclades éticas del género en el mejoramiento social. El estudio más extenso del periódico es la "Memoria" de García Parra sobre la literatura y las bellas artes, examen tanto de sus caracteres como de sus manifestaciones principales en la antigüedad. Otros trabajos de menor extensión, pero de cierta significación para la cultura guatemalteca aparecieron bajo las firmas de Manuel Montúfar, Miguel García Granados y el abate E. G. Brasseur de Bourbourg. El primero escribió en dos números de El Mıséo sobre "Derecho internacional" (II, Nos.

el Br. Domingo Juarros; y Rico y pobre, 1859, del francés Emilio Sauvestre y traducida por Manuel Diéguez.

12 Según David Vela el autor de estas conferencias es el Lic. José Domingo Diéguez, padre de los poetas Juan y Manuel Diéguez. La obra data de 1833 , y no se publicó en El Museo en 1856, como dice Vela, sino en 1857. Véase Vela, Literatura guatemalteca, 2 ed., Guatemala, Tip. Nacional, 1944, II, p. 181. 
I2 y I3, I857) y poco después "Una tarde de invierno. Subiendo de Panachel a Sololá" (II, No. 36, 1857), bella descripción ce la región y del lago Atitlán. ${ }^{13}$ El ilustre patricio liberal Miguel García Granados colaboró con un llamamiento a la unidad centroamericana en "Centro Amśrica. Su situación actual y medios de mejorar su porvenir" (I, No. 34, I 857). Y del abate Brasseur, el descubridor del "Rabinal-Achí", se incluyeron "Resumen histórico y cronológico de los reyes de Guatemala antes de Ia conquista" (I, No. 29, I857) y "Nociones de un viaje a los Estados Unidos de San Salvador y Guatemala" (I, Nos. I7, 4I y 42, I857), este último traducido por el poeta Manuel Diéguez. ${ }^{14}$ Nada se dice en El Museo del descubrimiento de la famosa obra dramática quiche, representada en la iglesia de Rabinal el año anterior, el día 25 de enero.

Entre los autores arriba citados merece mención especial Fernando Velarde. Nacido en la provincia de Santander, Velarde residió largos años en América ejerciendo al parecer gran influencia como profesor y como poeta en el Perú y en Guatemala. En la ciudadi de Antigua, Guatemala, fundó y dirigió un colegio que, de I854 a I860, acogió a "lo más granado de la juventud de aquella época"15 dejando un buen número de discípulos, admiradores no sólo del educador sino también del autor de Melodias romanticas ( 1856 ) y Cánticos del Nucvo Mundo ( 1860 ). Velarde, aunque escasamente conocido en su tierra natal, comparte con otros compatriotas de mayor reputación literaria la representación española en las páginas de $E l$ Museo, codeándose en tal

13 Manuel Montúfar Alfaro (?-1857), juez de Sololá, es también autor de la novela $E l$ alférez real, de la que se publicaron solamente las cuatro primeras entregas en la Imprenta de Luciano Luna, en 1858. Por esta cbra se le puede considerar el precursor de la novela histórica en Guatemala. Al parecer poséía los manuscritos de Montúfar, Manuel Rivera, quien publicó el prólogo en $E l$ Museo (II, 10, 1858). Véanse Vela, Literatura guatemalteca, 2 ed., II pp. 374-377: Seymour Menton, Historia critica de la novela guatemalteca, Guatemala, Edit. Universitaria, 1960 , p. 22; y Valenzuela, Bibliografía guatemalteca, Guatemala, Tip. Nacional, 1961, V. p. 165.

14 Además de los mencionados deben incluirse unas disquisiciones de carácter histórico-filosófico firmadas con el seudónimo de Fray Jerundio y titulada "La civilización" (I, Nos. 20-28, 1857); "Estudics sobre la sinonimia castellana", de M. B. de los Herreros (I, No 2, 1856); v "Ránida ojeada scbre el porvenir social" (II, 8, 1858); y "La religión y la pública felicidad" (II, 10, 1858), de Miguel Boada y Balmes.

15 Ramón Urirate, Griería poética centroxmericana, Guatemala, Tip. 'La Unión", 1881, I, 301-302. De Velarde se incluyen en El Museo: "A la Srita. Da. Cecilia de Masson (I, 9, 1856), "A Dics" (I, 18, 1857), "A. C." (II, 1. 1858, LyV), "Fragmento de una composición a la cordillera de los Andes" (II, 3 , 1858, LyV), "Con motivo de haberse suicidado el Sr. Francisco Pineda" (II, 5, 1858, LyV), "Contemplando el cadáver de un niño", Fragmento (II, 7, 1858, IyV). 
sentido con Alberto Lista, Angel de Saavedra, Manuel Bretón de los Herreros, Juan Donoso Cortés, Gregorio Romero de Larrañaga, Francisco Camprodón, José Zorrilla, Ramón de Campoamor y Luis Mariano de Larra, entre otros. La revista recogió asimismo producciones de otros escritores europeos en traducciones al español hechas, si no todas, algunas de ellas, por guatemaltecos. Esas traducciones incluyen pensamientos de La Rochefoucauld y Chateaubriand, fragmentos de Klopstock y de Mazzini, poesías de Chénier, Hugo o autores no identificados.

Exceptuacia la producción guatemalteca, es muy posible que una buena parte de la obra poética de lengua española de El Museo provenga de diversas publicaciones de la época. Sin intentar un estudio detallado al respecto podría decirse que entre las fuentes principales se cuentan revistas mexicanas de las décacias del cuarenta y del cincuenta, como ilustran los ejemplos siguientes de La ilustración mexicana y El espectador mexicano. En La ilustración mexicana habían aparecido en I85I "Las estrellas", de Francisco Camprodón, que El Museo reproduce en I856 (I, No. 7) y "Delirios", del mexicano José María Mora, impresa en El Musea de 1857 (I, No. $4 \mathrm{r}$ ); en tanto que en 1852 , se publica "A un árbol", de Enrique Saavedra, también mexicano, incluida en El Museo en 1857 (I, No. 27). Por lo que respecta a El espectador mexicano, en 185 I aparece en sus páginas el soneto de Zorrilla "A María", y en 1857 lo trae $E l$ Museo (I, No. 37). Préstamos semejantes deben haber ocurrido con algunos de los trabajos en prosa, puesto que el "Fragmento de Mazzini", que ve la luz en El Museo (I, 28, I857) es el mismo de La ilustración mexicana de $185 \mathrm{I}$ (págs. 37-38). También ciertos temas, como el cel famoso dux florentino Marino Faliero, tienen probablemente idéntica procedencia, según sugiere su popularidad en las revistas mexicanas ya citacias y en otras como El apuntador, de I 84 I. $^{16}$

Si El Musea queda como ventana abierta al panorama de la cultura guatemalteca durante la década de 1850 , su publicación conserva para la posteridad la labor poética de algunos autores nativos, de varia importancia, pero que, en su gran mayoría, no había coleccionado su obra, o no lo haría jamás. La figura de mayor relieve es indudablemente Juan

16 De otro mexicano, Emilio Reyes, se publicó en El Museo el soneto religioso "La Magdalena" (I, 11,57$)$, que no se cuenta entre sus colaboraciones a $E l$ álbum mexicano, de 1849 o a La ilustración mexicana, de 1851, aunque es muy probable que haya aparecido en alguna otra revista de entonces. Sí se incluve, por supuesto, con algunas variaciones, en sus Poesías, México, "El Globo", 1868, p. 267. De La ilustración se toman, sin embargo, breves biografías de Dumás y de Humbaldt publicadas en El Museo, II. Nos. 9 y 11, 1858. 
Diéguez Olaverri (1813-1866), quien aćemás de sobresalir entre los poetas de esos años se destaca como uno de los principales de Guatemala en el siglo. Pobre toda la vic̀a, añadió a sus infortunios un espíritu liberal que lo llevó a conspirar contra el dictador Carrera, y a sufrir por ello prisión y exilio. De las veinte composiciones suyas que aparecen en El Museo de 1856, nueve, por lo menos, fueron escritas durante ese período de extrañamiento en el estado mexicano de Chiapas. $Y$ entre ellas se hallan algunas de las más famosas.

Los tres temas fundamentales de Diéguez, la naturaleza, la patria y el amor están representados en $E l M l u s e O$, aunque no siempre separados con tal nitidez, por supuesto. La naturaleza es a menudo su tema síntesis, puesto que en él se incluyen no pocas veces los otros dos, y tanto la patria como el amor se funden con frecuencia en la añoranza de la familia ausente. La tonalidad lírica predominante del poeta, la melancolía, es también evidente.

La única composición de Diéguez que representa exclusivamente el tema de la naturaleza en El Museo es "El bosque" (I, 44, I857), cuadro de majestad salvaje en el que la eternidad del medio natural surge ante el poeta en constraste con "jeneraciones mil" que han volado al olvido.

Aunque no exactamente dentro de la clasificación anterior, podría incluirse en ella otra composición de acusados rasgos románticos. Titulada "La noche", esta obra comienza con una impresionante descripción del espíritu nocturno, personificado en un dios negro que guía su regio carruaje tirado por vampiros inmensos:

Melancólico rueda y silencioso, por las frías llanuras celestiales, un enlutado carro majestuoso, tirado por vampiros colosales. Bajo su solio de sublime duelo, de fúlgidos diamantes tachonados, la faz cubierta de sombrío velo, gobierna una deidad el carro alado.

Tan negros como él, y como él bellos, lleva sobre los hombros esparcidos los ondulantes húmedos cabellos, que rozan el crespón de sus vestidos. 
De ébano empuña cetro soberano

la diestra con que rije el vasto imperio, y los pliegues desvuelve su otra mano del manto con que cubre el hemisferio.

$$
(I, 32, \text { I857). }
$$

Si el resto de "La noche" se aparta de la naturaleza en una meditativa misantropía que se acoge a la soledad y a las tinieblas como a un refugio, queda, sin embargo, la importancia de esos endecasilabos iniciales que recrean la magnificencia del misterio nocturno.

Las dos composiciones más famosas de Diéguez, "La garza" y "A los Cuchumatanes", se publican con algunos meses de diferencia en I857, reflejánćose en ambas la tristeza del exilio. Pero entre ellas se mencionarán otras poesías que establecen una gradual elaboración del tema de la naturaleza. "La garza" (I, Io, 1857 aparece en lo que podemos considerar como su versión original, que es la que se utiliza en la primera edición de las Poesías de Diéguez, publicadas en $1893 .{ }^{17}$ Tiene entonces veinte y ocho estrofas y muestra ciertos cambios en comparación con la versión posterior, de cuarenta y nueve estrofas, consagrada por Ramón Uriarte en su Galeria poética centromericana (I873 y 1888), Menéndez y Pelayo en la Antologia de paetas bispanoamericanos (1892) y Humberto Porta Mencos en el Parnaso guatemalteco (1928). ${ }^{18} \mathrm{La}$ menor extensión de la versión original, no siempre conocida o recordada, ha llevado a algunos a considerar mutilado el poema en la edición će ı893. Tanto en la versión original de El Museo y de Poesícs (1893) como en la posterior el poeta comienza por captar lo que en realidad es su propia melancolía y soledad en el ave inmaculada que contempla, en un caso típico de identificación romántica con la naturaleza. Así ditá en El Museo:
Imagen de pesar y de inocencia, siempre a mi corazón interesante;
yo mustio como tú, cual tú infelice, yo de cantarte he, mísero vate.
Pláceme verte en la apacible orilla,

17 Juan Diéguez, Poesias, Guatemala, Tip. Nacional, 1893, pp. 86-91.

18 Al parecer la versión aceptada fue apadrinada por el famoso novelista y crítico literario Jcsé Milla. Así lo sugiere Uriarte al confesar que a pesar de preferir la primera versión incluye en su antología la segunda por consideratla Milia superior. Uriarte, Galería poética centro-anericana, I, 156, Parạ "La garza" vẹ́arse las pp. 172-178. 
como un ampo de nieve entre cristales, inmóvil, dolorida y silenciosa, reflejo de mis íntimos pesares. (p. 7).

Mientras que en la versión definitiva ${ }^{19}$ se limitará a alusiones más breves en dos estrofas no consecutivas:

El destino a tus playas solitarias condújome tal vez porque te cante, y mustio como tú, cual tú infelice, yo de cantarte he, mísero vate.

El color te inspiró más dulce y manso su elegíaca expresión tan penetrante; tu actitud modeló melancolía, inocencia te dio tu albo ropaje.

(pp. I34 y 135 ).

Luego atraviesan por su mente los peligros del cazador que acecha a la garza y de la tiranía que lo persigue a él:

Víctima del instinto carnicero del feroz cazador, temprano o tarde Serás, jay Dios! y tu nevada pluma, enrojecida en tu inocente sangre.

Mañana, o esta noche, quizás ahora, el hado ejecutivo me arrebate... ¿Y cuál asilo substraerá mi sueño De mi existencia errante a los azares? (El Museo, p. 8).

Aquí se debe observar que la alusión de carácter político se diluye en el anodino lamento romántico sobre el ciestino y la vida errante. Por lo que cabe preguntarse si estamos ante un eufemismo impuesto por la dictadura cie Carrera o si se trata, simplemente, de la primera forma que

19 Utilizamos aquí la obra de Humberto Porta Mencos, Parnaso guatemal. teco, Guatemala, Tip. Nacional, 1928, 
toma su inspiración. Lo cierto es que en la versión de Uriarte de 1873 la alusión política es completamente diảfana:

Tal vez mañana por lejanos climas

huyendo vaya de la ley del sable, si estas montañas de la paz asilo, también atruena la civil barbarie.

(Porta Mencos, p. 136).

Una vez en el plano mental del peligro que amenaza, de la incertidumbre, surge el contraste inevitable, y lógico, entre la efímera existencia del ave espejo y de sí mismo, por una parte, y la aparente perennidad del lago y su vegetación, por otra:

La onda ya no verá su blando lirio, y faltará el cantor del lirio amante:

nadie su ausencia notará del lago donde todo prosigue inalterable.

$$
\text { (El Museo, p. 8). } .^{20}
$$

Así se llega a la estrofa final, oprimida aparentemente bajo la tristeza del exilio en $1857 \mathrm{y}$, por consiguiente, con la muerte como obsesión:

$Y$ en tanto, ; oh alba flor de la laguna, sepultura entre flores $\mathrm{y}$ cristales

a tí conceda bondadoso el cielo,

y a mí el morir en brazos de mi Madre!

(El Museo, p. 8).

influida por perspectivas más alentadoras, con alientos de vida y de esperanza en su versión posterior:

Alli, oh amiga, bondadoso el hado

largo vivir sin inquietud te guarde

20 La versión más conocida dirá en su estrofa 25:

¡Tú y él qué fueron sino arenas leves, que la onda trajo y que los vientos barren?

Tú y él borrados de la leda estancia, ella por siempre quedará inmutable.

(Porta Mencos, p. 137), 
y un fin tranquilo entre tu nido de algas,

y a mí en los brazos de mi dulce madre.

(Porta Mencos, p. I40).

Es digno cie observarse que, en la vida o en la muerte, la madre surge como el refugio soñado, lo que revela el profundo afecto de Diéguez por la que le dio el ser, y su dependencia emocional en ella, así como el probable valor simbólico de la progenitora, con toda probabilidad encarnación también de la patria.

Aunque las diferencias principales entre las dos versiones de "Ia garza" se encuentran en la expresión más bien que en las icieas, ${ }^{21}$ las estrofas 9, I I y I5 de la primera han sido omitidas enteramente de la segunda, en tanto que ésta, con casi doble extensión que aquélla, añade, entre otros pasajes el de las estrofas 35 a 48 , dedicadas en gran parte a una tradición romántica de amor maternal y elementos sobrenaturales.

La naturaleza tropical y salvaje de esta composición es un bello ejem. plo de romanticismo americano. Por su delicadeza y por su suave tonalidad viene acaso de Hugo y de Bécquer, mas se halla en tránsito hacia el Tabaré de Zorrilla de San Martín y hacia el Alma América de Chocano, quizás hacia el modernismo, pero indudablemente con lo mejor de todos ellos.

Semejante visión de lo grandioso en el panorama agreste de América es indiscutiblemente una de las cualidades más apreciables del poeta; siendo otro de sus grandes logros la deliciosa fiesta primaveral de "Las tardes ce abril", desafortunadamente no incluida entre sus colaboraciones de $E l$ Mirseo.

La contemplación de la naturaleza y el hombre que en ella busca alivio a su color están presentes en "El amante de la naturaleza" y "El arroyo" en lo que, partiendo de "La garza" puede considerarse una escala ascendente de importancia para el elemento humano. En la primera versión de "La garza" la atención del poeta se concentra en el ave hasta que el crecer de su melancolía encuentra el paralelismo identificador de sus destinos. Por el contrario tanto en "El amante de la naturaleza" como en "El arroyo" el equilibrio se ha roto ya a favor del poeta, cuyo lirismo desbordado contempla el panorama en busca de la dualidad naturaleza-dolor humano, y todas sus posibilidades como lenitivo al

21 El número de estrofas de la segunda yẹrsión se explica ẹn ciẹrtos cạsos pof su mayor prolijidad, 
pesar. En estas composiciones la naturaleza es asilo en la desdicha, seno que recibe la cansada cabeza del bardo errante:

Pues que víctima he sido

del destino más rudo,

y protervia hincó en mí su diente agudo,

y triste el corazón, pálido y yerto,

de fúnebre sudario fue cubierto;

viene a tí la alma mía,

viene a tu amante seno,

de amor, de dicha y de hermosura lleno,

¡Oh bella sin rival, Naturaleza!

A olvidar de sus males la fiereza.

Que eres tú para mi alma, en sus crudos dolores,

la "Ninfa de los últimos amores",

que encanta con celeste melodía

el sombrío terror de la agonía.

o compañera ideal del solitario:

¡Ay, sí! mientras que canta

sus amores el ave,

murmullas tú, y el céfiro suave

acaricia tus ondas y mi lira,

el llanto brota, el corazón respira.

Dulces silvestres tonos, no del arte harmonía, que siempre conmovieron la alma mía!

a su compás, arroyo cristalino,

gusto cantar nuestro común destino.

$Y$ en soledad sabrosa,

dueño de mí, un momento,

contigo y con mi triste pensamiento,

a tí, mi lloro doy; al aire el canto,

$y$, un instante, al olvido mi quebranto. 
Adiós, fugaz arroyo:

la noche pavorosa

ya sobre tu onda cae silenciosa:

ya vuelve el pajarillo al culce nido,

y yo, ce ingrato mundo, al vano olvido.

Y si en la primera aflora un instante la pena del proscrito, consciente de la crueldad de su especie - iSiempre crueles los hombres y tiranos / con la inerme inocencia, aún los que siendo / víctimas de tiranos van huyendo!- en ella se revela ya la identificación doliente del hombre y del paisaje:

Y lloré en el laúd de la tristeza, mis lágrimas cojió límpida fuente: suspiré con la brisa tiernamente del solitario monte en la aspereza.

Sentado entre la lóbrega quebrada respondí con la voz de mi jemido al monótono canto dolorido de lúgubre espumuy desconsolada.

A la margen canté de la laguna de su cándida Garza la inocencia, y orillas cel arroyo la violencia que nos urje a él y a mí desde la cuna:

desde el umbral de mi infeliz cabaña, y a la pálida luna de verano, oyendo al cuerpo-ruin dolerse en vano, con mi triste canción le hice compaña.

en tanto que en la segunda el arroyo es símbolo de la humana tragedia, mártir del mismo destino:

$¡$ Oh peregrino arroyo,

Imagen de mi vida!

¿Por qué va tu corriente tan urgida?

¿Qué, te precisa abandonar las flores

dẹ esta risueña orilla y sus amoręs? 
¿Qué falta ya a tu canto?

¿Qué falta a tu ventura?

¡Tente: gózate en ella mientras dura!

Gózate en la belleza y harmonía,

Brisas y sombra, flores y ambrosía!

¡Ay! durarán tus glorias

lo que la vana espuma,

y arista, sin que el fuego la consuma:

duran más los amores de la brisa:

no haces mas que pasar, pasar de prisa;

$Y$ ceder al impulso

terrible que te obliga

de la que viene atrás, oncia enemiga;

y que no más feliz, que lo fue aquélla,

a otra cede también, que la atropella.

Mas no hay para tí amores,

ni reposo un instante:

¡Correr, siempre correr. . . siempre adelante!

$Y$, adielante! que clama the parece

una terrible voz que me estremece.

¡Oh la voz del Destino... !

del destino la mano,

como a la prometida del Oceano,

Sin piedad por la víctima inocente,

te arrastra a sus abismos inclemente.

"A los Cuchumatanes", inspirada en la sierra de ese nombre entre Guatemala y Chiapas, se publica en $E l M u s e$ en su forma definitiva de nueve octavillas heptasilábicas abbcdeec. En ellas las brumas del crepúsculo vespertino que van cubriendo lentamente las montañas, acaban por sentirse como brumas del alma, más bien que del paisaje, en el desconsuelo del poeta por el distante hogar materno, imagen de los primeros años y, como en "La garza", de la patria. Lạ naturalęza, en sí, es ape- 
nas velo transparente, alusión más que presentación, ya que lo fundamental es esa amargura de amor filial nostálgico por el tronco familiar, que es aquí la tierra nativa en su calor humano:

¡Cuán dulcemente triste

mi mente se extasía, oh cara Patria mía, en tu áspero confín!

¡Cuál cruza el ancho espacio, ay Dios, que me separa de aquella tierra cara, de América el jardín.

En alas del deseo por esa lontananza, mi corazón se lanza hasta mi pobre hogar. ¡Oh dulce madre mía, con cuanto amor te estrecho contra el doliente pecho que destrozó el pesar!

$¡$ Oh, vosotros que al mundo conmigo habéis venido, dentro del mismo nido, y por el mismo amor; y por el mismo seno nutridos y abrigados, con los mismos cuidados, arrullos y calor!

¡Oh cielo cie mi Patria!

¡Oh caros horizontes!

¡Oh ya dormidos montes! la noche ya os cubrió: adiós, oh mis amigos, dormid, dormid en calma, 
que las brumas en la alma, ¡ay, ay! las llevo yo.

(I, 30, I857, p. 7 ).

Angustia semejante, aunque limitada a la persona del hermano, exilado en el Salvador, expresan las liras de seis versos de "A mi hermano Manuel", escritas en Comitán, Chiapas, en 1846 , y publicadas en El $M u$ seo en $\mathrm{r} 857$ (II, $\mathrm{n}^{\circ} 4^{2}$ ).

El amor ofrece en la producción de Diéguez la doble vía sentimental de lo filial y de lo erótico. En su primera manifestación es, como se ha expresado anteriormente, síntesis usual de patria y hogar materno, si bien no falta la expresión autónoma del segundo. Recuérdese el delicado final de "A una mosqueta", voz dolorida y caballeresca del hijo amante:

Descolorida flor, marchita y triste, flor con quien hablo en mi delirio vano, flor que hasta aquí buscándome veniste, flor que cortó mi Madre con su mano:

si del recuerdo la punzante espina lastima el pecho a tu infeliz cantor, tus ojos le embalsaman flor divina, con la suave ambrosía del amor.

$$
\text { (I, 36, } 1857, \text { P. 6). }
$$

Lo sentimental erótico es patrimonio de unas octavillas hexasilabas tituladas "La majia del amor" ( 1 , I5, I857) y del soneto "Los ojos" (I, I9, I857). Dirigidas ambas poesías a Clori, exalta aquélla la magia consoladora de la amada que convierte en arcadia el cesierto de su vida, en tanto que canta éste el tormento adorado de sus ojos. No se cuentan estas composiciones entre las mejores del poeta no obstante la agradable facilidad de la primera y la cierta notoriedad de que goza la segunda, El soneto es más bien un ejercicio poético en realidad poco feliz, cuya idea principal no es otra que la del famoso madrigal de Cetina y en el que cada verso comienza con la palabra "ojos". Amorosa también podria considerarse 22 "El pino seco y el quiebra cajate" (I, 3, I856), alegoría de la enredadera que se abraza al pino abandonado como último vesti-

22 Si la enredadera se refiere a la amada o a la esposa, ya que podría referirse a una hija en cuyo caso habría que incluirla entre sus obras anteriores de amor filial. 
gio de la muerta primavera. La congoja implícita en la conciencia de ser ésta la única ilusión que sobrevive en su azarosa existencia y el temor de que desaparezca pronto como las otras constituyen modalidades de esa tristeza romántica, de un romanticismo vivido no asumido, que informa gran parte de su producción. Así se evidencia casi sin excepción en el resto de sus poesías de $E l$ Museo, sea ya en "La sonrisa" (I, 2, I856), para el poeta paloma desbandada, flor olvidada por el aquilón; o en "El cólera" ( $I, 38, x 857)$, amenaza no sólo de su vicia sino de los seres queridos, como él expatriados. Ya en "Pensamiento de una tarde" (II, 6, I858, LyV), donde aflora su fe religiosa y su ansia de serenidad en el trance supremo de la muerte; o en "La estrella de la tarcie" (I, I5, I857), en la que el astro vespertino es otra garza que refleja la tristeza y la desilusión del autor. Presente de la misma manera en la poesía amorosa citada antes, aunque con las variedades propias del tema, se refleja igualmente en "El cisne. Canto alegórico a la muerte del poeta A. Chenier" ( $I, 28$, I857) y en los desilusionados endecasílabos sobre el destino del genio en "A la memoria del retratista don Francisco Cabrera" ( $\mathrm{I}, \mathrm{I} 3$, I857). Por excepción no es la nota esencial en "Oda a la amistad" ( $I, 45, \mathrm{I} 858$ ), pero en un sentido negativo está allí también como el único sentimiento que dulcifica y anima su "penosa existencia", sus "funestos clias". 23

Como su hermano Juan, Manuel Diéguez Olaverti (I821-I86I) llevó una existencia dolorosa marcada por la prisión política, el destierro y finalmente la locura. ${ }^{24} \mathrm{Su}$ obra, no publicada en volumen, quedó dispersa en revistas de la época y en algunas antologías posteriores. ${ }^{25}$ Es de un carácter patriótico o familiar, cuando no de un erotismo desilusionado y doliente en el que la amada ausente, infiel o muerta, juega papel principal. De las tres composiciones suyas que se conservan en El Museoo, "Un adiós" ( $(1,20$, I 8.57) y "A D ..." (I, 35, I857) lloran la falsedad o indiferencia femeninas, quedando sin representación en la

23 En El Museo se incluye igualmente la fábula "La encina y la caña" (II, 2, 1858, LyV), traducida por Diéguez de La Fontaine. La profesora Margarita Carrera de Wever ha publicado las composiciones de este autor en Corpus poeticum de la obra de Juan Diéguez, Guatemala, Imp. Universitaria, 1959. La edición lleva un extenso estudio titulado "Temática y romanticismo en la poesía de Juan Diéguez". Las dos versiones de "La garza", se incluyen en las pp. 170-179.

24 Participó con Juan en la conspiración contra el general Carrera, per lo que sufrió también prisión en el castillo de San José, viviendo más tarde desterrado en Ccmitán, Chiapas, y en San Salvador. Fue traductor de novelas v dramas franceses. Como el poeta cubano José Jacinto Milanés pasó los últimos días de su existencia en las tinieblas de la demencia.

25 Véanse principalmente: Uriarte, Galeria poética centro-americana, I, pp. 269-300 y Porta Mencos, Parnaso guatemalteco, pp. 149-153. 
revista el dolor por la amante desaparecida de otras poesías como "A la noche", "Las lágrimas" o "Las cenizas". La tercera de las composiciones de El Museo, "AlS. Jeneral D. José Víctor Zavala" (I, 35, I857), es una exaltación patriótica del General Zavala, vencedor del filibustero estadounidense William Walker.

En contraste con la existencia errante y atormentada de los hermanos Diéguez, otro de los poetas guatemaltecos más conocidos de su tiempo, Joaquín Vasconcelos (1830-1878), pasó sus días alejado de la sociedad en una finca del Pacifico. Su soledad no le impició, sin embargo, el estudio de la naturaleza humana, y así lo atestigua su copiosa producción epigramática, tesoro de sus dotes de observador y de sicólogo. La sociedad de su época, por otra parte, no se refleja directamente en su sátira, dirigida más bien, y en un sentido tradicional, a las debilidades y las falsedades del ser humano, en general, o a la de ciertos tipos en particular.

Durante el año 1857 se recogieron en El Museo ocho de su epigramas, publicados bajo su nombre completo o bajo las iniciales J. V. Son en realidad una síntesis bastante representativa de su producción por cuanto zahhieren a la mujer, ciertas profesiones y el interés o la codicia. He aquí una muestra que combina sus dos blancos favoritos, la mujer y la codicia:

\section{TÁCTICA EFICAZ}

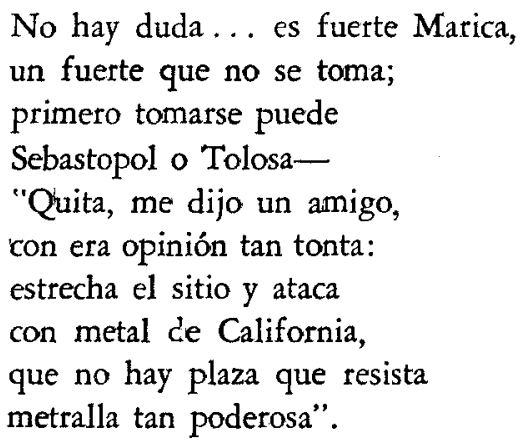

$$
\text { (I, 20, 1857). }
$$

Aunque no entre los epigramas más originales de Vasconcelos, quizás deba recordarse asimismo el titulado "Del mal el menos" (I, 21, 1857) por continuar en la poesía satírica guatemalteca la preferencia del arci- 
preste de Hita por las "dueñas chicas", la presente en la Gazeta de Guatemala (I, 30, 1797). ${ }^{20}$

Escribano de Cámara y Hacienda por muchos años y, según Ramón Uriarte, muy conocido en su tiempo, fue el poeta Francisco González Campos (1832-1904), otro de los colaboradores de El: Museo. Bien puede decirse que para esta revista González Campos es el cantor de la inocencia y de la caducidad de todo lo terreno, de tal manera que su lira desilusionada parece iluminarse de esperanza sólo en la fe de una patria futura mejor o de la existencia ultraterrena. La felicidad, como el amor, es en sus versos, algo lejano, gustado o perdicio en la mocedad; y el destino humano una fuerza que lleva a la maldad o a la muerte. ${ }^{27}$ No hay aquí huellas de sus letrillas y epigramas satíricos, y mucho menos de su poesía patriótica posterior inspirada en ideales liberales y de unidad centroamericana.

Entre varios poetas contemporáneos representados en El Museo, casi sin excepción, con una sola poesía, se cuentan Rafael Machado (1834-?), Manuel Zavala (?), y Jesús Laparra (I820-1887). Machado, que ocupó importantes cargos públicos durante el gobierno conservador de los treinta años, se estableció en Costa Rica en 1872 , tras el triunfo de la causa liberal, y allí fue catedrático, periodista y ćiplomático. Su única contribución poética a la revista fueron los alejandrinos aconsonantados de "El arco iris" (I, I, I856), expresión de su certeza en la presencia divina. Para adquirir una visión más completa del autor habría que mencionar el recuerdo nostálgico de la esposa arrebatada por la muerte, su contemplación de sentido filosófico o religioso de la naturaleza, sus evocaciones históricas y su actitud melancólica, desencantada, templada sólo por el cariño de los hijos y, sobre todo, por su fe religiosa. ${ }^{28}$

26 Para sus poesías véanse Uriarte, Galería poética, II, p.p. 69-92 y Porta Mencos, Parnaso, pp. 159-162.

${ }_{27}$ Véanse especialmente "Conserva tu candidez" (I, 26, 1857), "La vida" (I, 19, 1857), "A Guatemala" (II, 12, 1858) y "El arroyuelo" (II, 16, 1858 LyV). También lo incluyen en sus antologías Uriarte, Galería poética, II, pp. 93-159 y Porta Mencos, Parnaso guatemalteco, pp. 173-180. En Guatemala se hicieron dos ediciones de sus obras: Colección de poesias, Imp. de la Paz, 1860, 156 págs. y Tip. Nacional, 1913, 314 págs.

28 De Machado conocemos dos libros de versos, Amor, esperanza y fe, Costa Rica, 1875, y Poesías, 2 ed. aumentada, San José, Costa Rica, Imp. de José Canalías, 1887. Esto último incluye toda su producción. Selecciones de sus versos pueden leerse en las siguientes antologias: Uriarte, Galería poética, pp. 235-268, Máximo Fernández, Lira costarricense, San José, Tip. Nacional, 1891, II, 143. 246 y Porta Mencos, Parnaso guatemalteco, pp. 181-193. Rafael Machado es el autor del ensayo sobre "Literatura" ya mencionado anteriormente. Es probable que sea obra suya también la traducción poética "Paula" (I, 6, 1856) firmada con las iniciales $\mathrm{R}$. $\mathrm{M}$. 
De Manuel Zavala muy poco sabemos, excepto que se ećucó en los Estados Unidos, estudió derecho en Guatemala y, tras ocupar algunos empleos públicos, murió muy joven, años antes de $1879 \cdot{ }^{29}$ En su número correspondiente al I9 de octubre de 1858 (I, № I2) El Museo dice: "Con motivo de la colocación del telégrafo submarino, a través del Océano Atlántico, un guatemalteco compuso el siguiente soneto" y a continuación se inserta el titulado "A la colocación del telégrafo submarino a través del Océano Atlántico", de M. Zavala. El soneto en cuestión alaba tanto la bravura del descubridor de América como el ingenio anglosajón. Es una de las muchas composiciones escritas ciesde fines del siglo xvir en homenaje a los progresos científicos de la época. Su secuela, titulada "Al estreno del telégrafo submarino a través del Océano Atlántico", y dedicada también al talento anglosajón, se incluyó poco después en la parte literaria y de variedades publicada por entregas (II, I5, r858). Ambos sonetos aparecieron, veinte años después, en la famosa publicación El porvenir (I, 16, 1878). Antonio Batres Jáuregui, en su Literatura americana (1879), comenta con sorpresa el hecho de que Manuel Uriarte no incluya a Zavala en su Galería poética centroamericante (I873 y I888); pero él mismo, aunque habla brevemente de Zavala y lo consiciera buen conocedor de las reglas de expresión, se limita a mencionar únicamente los dos sonetos antes citacios. ${ }^{30}$ Sospechamos que muy poco se conoce del resto de su obra.

En 1858 la sección de variedades y literatura de El Mizseo publicó entre julio y diciembre diez composiciones de María Josefa García Granados, al parecer en homenaje al décimo aniversario de su fallecimiento. Entre tales poesías predomina una tendencia discursiva que halla cierto deleite melancólico en la contemplación de la naturaleza; se indigna ante la inocencia, o la pureza, mancillada; se detiene en la introspección, o en la meditación ce tinte filosófico y, en ocasiones, revela su admiración por algún intelectual notable, narra desastres o canta el desgarramiento de las despedidas. Si la mayoría de los temas anteriores acusa un delicado temperamento femenino sensible a la belleza también se evidencia en ellos la inquietud amorosa, presente por lo menos en cinco de las diez poesías de $E l$ Musseo, y completamente emancipada de elementos extraños en "La resolución", cuyo asunto es semejante al de Gertrudis Gómez de Avellaneda en "Amor y orgullo" (1847). Como en el caso ce la cubana,

29 Antonio Batres Jáuregui, Literatura americana, Guatemala, Tip. "El Progreso", 1879, p. 328. 
y salvando las distancias estéticas que las separa, la entonación lírica de esta guatemalteca "hija del Betis" es más bien clásica y contenida. ${ }^{31}$

A la infortunada poetisa Jesús Laparra (1820-1887) se le dio cabida en la sección de entregas, ya mencionada, con unos laudatorios cuartetos endecasílabos a Zorrilla, nada representativos de su patética congoja lírica. ${ }^{32} \mathrm{Y}$ de D. R. Hernández, se incluyó la fábula " $\mathrm{La}$ ambición".

Del médico y poeta colonial Cristóbal de Hincapié Meléndez (fines del XVII-?) se incluyó en los números I I y 12 će I 858 la "Breve relación del fuego, temblores y ruina de la muy noble y real ciudad de Caballe. ros de Santiago de Guatemala" (I 7 I 7 ). Como ha observado Agustín Mencos Franco, sin contarse entre las luminarias coloniales, Cristóbal de Hincapié demuestra cierta originalidad al apartarse de la poesía religiosa o cortesana, ${ }^{33}$ si bien debe añadirse que no deja de ser un simple poeta de circunstancias y, por lo tanto, muy de su época. Su presencia en El Muséo tiene sencillamente un valor histórico.

Aunque no nacido en Guatemala, merece incluirse entre los poetas nativos ce El Museo, al nicaragüense Antonio Aragón (r835-?), profesor de idiomas y residente en el pais de 1859 a $r 863 .{ }^{34}$ Sus producciones, que incluyen un trabajo en prosa, se publican durante casi toda la vida literaria de la revista, desde 1856 hasta 1858 , y llegan a un total de once. Novelista y dramaturgo, según Uriarte, ${ }^{35}$ es uno de los más entusiastas discipulos de Fernando Velarde, como demuestra su algo exagerada alabanza del español en "El cisne ce Cantabria" (I, I7, I857). La possía de Aragón no es en realidad diferente a la de los otros autores previamente mencionados, cantando ya su tristeza por algún amor perdido o por la niñez lejana, ya sentimientos de amor platónico, con frecuentes referencias a su soledad, melancolia y desilusión. ${ }^{36}$

30 Ibid., pp. 328-329.

31 De su obra de El Museo, sección de "Litetatura y Variedades", recortemos solamente "A la ceiba de Amatitlán" (II, 8, 1858), "Plegaria" (II, 11, 1858), "A la esperanza", "La resolución" (II, 12, 1858) y "Descripción de la erupción del Cosigüina" (II, 13, 1858).

32 "Al célebre poeta don José Zorilla" (II, 14, 1858). Conocemos dos ediciones de sus poesías: Ensayos poéticos, Guatemala, Imp. Nueva de L. Luna, 1854, 74 págs. v Ensueños de la mente, Guatemala, Imp. de Arenales, 1884, 119 págs. También hay composiciones poéticas en Decenario del Niño Dios, Guatemala, Imp. de Teracena, 1880, 36 págs.

3,3 A. Mences Franco, Literatura guatemalteca en el periodo de la colonia, Guatemala, Tip. Nacional, 1937, p. 171. Una detallada relación del poema se hace en las pn. 171-192.

34 Uriarte, Galería poética, II, 161.

35 Idem.

36 En Guatemala se imprimió su libro Suspiros del infortunio, Imp. de la Paz, 1858, 32 págs. 
El lamento por la juventud y la felicidad perdidas se puede considerar también el tema predilerto de otro poeta que se firma $\mathbf{M}$. Rivera y parece ser el mismo Manuel Rivera ya citado como editor de la novela de Manuel Montúfar. ${ }^{37}$

En contraste con el caudal poético de El Museo, el género narrativo es sumamente escaso, reduciéndose a obras más bien breves y -excluidas las diez fábulas mitológicas, mencionadas al principio de este capítulopredominantemente costumbristas. La única excepción es "Contienda entre el trabajo y la ociosidad" ( 1, No r8, r857), por Julián S. Milanés, "cuento moral" de sabor neoclásico en el que el joven Luis escoge sabiamente entre la ociosidad y el trabajo que se le presentan en cuerpo de mujer. La producción costumbrista es casi toda de intención humorística y, probablemente extranjera, destacándose por su gracejo ocasional, además de "El poeta lírico" (I, I5-16, I857), de Luis Mariano de Larra, otros dos artículos sin nombre de autor: "No tenga usted cuidado" 38 (I, 43, I 857) y "La viuda verde" (II, I3, I858), el último de los cuales parece ser mexicano. La obra del hijo de Larra es una graciosa descripción del nacimiento e infancia del poeta lírico, mientras que las otras dos tratan ciel nerviosismo de un joven tímido durante la epidemia de cólera, y de las artimañas de la viuda que no intenta serlo por mucho tiempo. Otro cuadrito costumbrista, de índole más bien satírica que jocosa es "El sábado" (I, I9, I857), de V. S. Ocaña, sobre la fiebre de limpieza semanal que hace huir de la casa a los maridos.

Si en la América Central de su época El Museo Guatemalteco no tiene paralelo como tesoro cultural, en la amplitud del siglo se destaca entre los esfuerzos cimeros del periodismo literario continental. Su publicación de dos años y meses, durante uno de los regímenes más retrógacos del continente, es, en sí, proeza de tenacidad -y hasta de supervivenciaintelectual. Porque en el ámbito nacional y centroamericano, después de la Gazeta de Guatemala (I797-I8I6) y antes de la aparición de El porvenir (1877-I88I), no se da un concurso igual de hombre de letras ni una producción semejante.

Tulane University

OTTO OLIVERA

37 Véase nota 14. Las poesías de Rivera en El Museo son: "La partida" (I, 2, 1856). "La juventud" (I, 4, 1856) y "Recuerdo del Ilmo. Sr. Pedro Cortés y Larraz" (I, 9, 1858).

38 Lo firma D. Mariquito. 